\title{
CONFLICTOS SOCIO-AMBIENTALES Y CULTIVO DEL BANANO. ESTUdio DE LA REgIÓN AtLÁntico/Caribe De Costa Rica, 1950-2017 ${ }^{1}$
}

\author{
Edgar Eduardo Blanco Obando ${ }^{2}$
}

\section{Resumen}

A partir del análisis longitudinal del metabolismo social, el estudio de la teoría de la conflictividad socio-ambiental y una amplia revisión de documentos técnicos, científicos y estadísticos, el artículo muestra cómo entre 1950 y el 2017 la producción bananera en la región Atlántico/Caribe de Costa Rica provocó el surgimiento de conflictos socio-ambientales, al excretar residuos de plaguicidas que contaminaron el ambiente, excluir a la población local de la explotación de la naturaleza y dañar severamente la salud pública. Este actuar de la empresa bananera fue interpretado por la población local como un atentado contra su subsistencia, lo que provocó su movilización para exigir al Estado el control del impacto ambiental del monocultivo.

1 Este trabajo corresponde a los resultados del proyecto de investigación "Actividades agroproductivas y movimientos socio-ambientales en la región Atlántico/Caribe costarricense. Estudio del período 1950-2017”, adscrito al programa Ambiente, Ciencia, Tecnología y Sociedad (ACTS). Intersección entre Historia Ambiental y Estudios Sociales de la Ciencia, la Tecnología y la Sociedad (CTS), del Centro de Investigaciones Históricas de América Central, con patrocinio de la Vicerrectoría de Investigación, de la Universidad de Costa Rica.

2 edgar.blanco@ucr.ac.cr Doctor en sociología por la Universitat Autònoma de Barcelona; docente e investigador sobre temas del medio ambiente y el desarrollo Centro de Investigaciones Históricas de América Central, Universidad de Costa Rica, Facultad de Ciencias Sociales, UCR, San José, Costa Rica, América Central. 
Palabras clave: agricultura; metabolismo social; medio ambiente; conflictividad social

\title{
Resum
}

A partir de l'anàlisi longitudinal del metabolisme social, l'estudi de la teoria de la conflictivitat socioambiental i una àmplia revisió de documents tècnics, científics i estadístics, l'article mostra com, entre 1950 i 2017, la producció bananera a la regió Atlàntic/Carib de Costa Rica va provocar el sorgiment de conflictes socioambientals per causa de l'abocament de residus de plaguicides que van contaminar l'ambient, de l'exclusió la població local de l'explotació de la natura i del greu perjudici contra la salut pública. Aquesta manera d'actuar de l'empresa bananera va ser interpretada per la població local com un atemptat contra la seva subsistència, la qual cosa va provocar-ne la mobilització per exigir a l'Estat el control de l'impacte ambiental del monocultiu.

Paraules clau: agricultura; metabolisme social; mediambient; conflictivitat social

\begin{abstract}
Based on a longitudinal analysis of social metabolism and environmental conflict, and after an extensive review of technical, scientific and statististical documents, the article shows that in the 1950-2017 period, large amounts of residues of pesticides from banana's plantations were filtered into environment, and caused contamination and damage to people's health. This situation caused environmental conflicts between communities, on the one hand, and corporations and the State, on the other, beacuse the local population interpreted that this type of agriculture jeopardized their health and social reproduction.
\end{abstract}

Key words: Agriculture; Social metabolism; Enviroment; Social conflict 


\section{Introducción}

En la región Atlántico/Caribe de Costa Rica, la producción extensiva de banano para la exportación ha sido una actividad con una importancia mantenida en el tiempo. Esta se inicia en las décadas finales del siglo XIX, involucrando a la importante compañía transnacional estadounidense United Fruit Company (UFCo).

A inicios de la década de 1870, el Estado costarricense deseoso de contar con una vía terrestre que conectara a San José, en el centro del país, con Puerto Limón, en el litoral Caribe, para lograr un acceso directo a los principales mercados mundiales a través del océano Atlántico ${ }^{3}$, encargó la construcción de un ferrocarril al estadounidense Minor C Kith, quien recibiría a cambio la administración y explotación del ferrocarril por prácticamente cien años, junto con la adjudicación de 500 hectáreas de terreno situado a ambos lados de cada kilómetro de línea férrea que construyera. Estas ventajosas condiciones fueron aprovechadas por el empresario para iniciar la actividad bananera de exportación (Rosario, 2015).

Con el acceso asegurado al principal puerto en el Caribe, el control del único ferrocarril del país y el disfrute de enormes extensiones de tierras, Keith se asoció con el empresario bananero Andrew Preston para fundar en Nueva Jersey Estados Unidos, la United Fruit Company (UFCo) en 1899. En poco tiempo la UFCo se convirtió en el rector de la actividad bananera en el país, y sentó las

3 Desde los primeros años del siglo XIX, incluso antes de la independencia de Costa Rica en 1821, el café ya era el principal producto de exportación, sin embargo, debido a la falta de vías de comunicación con el litoral Caribe, el grano debía de exportarse por el puerto de Puntarenas en el Pacífico costarricense, donde se dirigía primero a Chile y de ahí a las metrópolis europeas. Esta situación incrementaba los costos para los productores y reducía las divisas para el país, por lo que era indispensable construir una vía al Caribe y así tener acceso directo a los principales mercados mundiales a través del océano Atlántico. 
bases para que el monocultivo se consolidara como una de las principales actividades productivas en la región.

A pesar de la bonanza inicial de la actividad, a finales de la primera mitad del siglo XX la UFCo debió enfrentar serias adversidades que redujeron considerablemente su producción, como fueron la crisis mundial de 1929, la plaga el Mal de Panamá, constantes protestas de los trabajadores por las pésimas condiciones laborales, y el desgaste de los suelos. Estos factores obligaron a la transnacional a prácticamente abandonar sus operaciones en la región Atlántica durante la década de 1940, y a trasladarse al sur de la provincia de Puntarenas, en el litoral Pacífico, donde encontraron mejores condiciones para continuar con la producción extensiva de la fruta.

Para solventar las consecuencias del retiro del principal actor económico en la región, el Estado recurrió a incrementar sus inversiones en obras públicas y en la creación de colonias agrícolas en las tierras que la compañía iba abandonando, con el fin de reactivar los sistemas productivos, repoblar espacios abandonados y diversificar la agroproducción. Se asignaron también recursos a los productores nacionales de banano para que incrementaran sus operaciones y así devolver el dinamismo perdido al monocultivo (Montero y Viales, 2010). Y se promovió la llegada de otras transnacionales bananeras, como la Standard Fruit Company que se asentó en la región en 1956, trayendo consigo nuevas técnicas de cultivo y una variedad de banano resistente al Mal de Panamá. En 1965 llegaron la Bandeco y la Cobal, que también aportaron para que el cultivo del banano volviera a consolidarse como actor clave en el sistema agroproductivo local (León, 2012). 
De acuerdo a los censos agropecuarios realizados en el país en 1950, 1963, 1973, 1984 y en el 20144, los resultados de las acciones emprendidas por el Estado para reactivar la producción bananera figuran hasta 1963. En 1950 el banano no aparece entre los principales productos agrícolas de la región (DGEC, 1950)

Para 1963, el banano (4.262 ha) ocupó el cuarto lugar entre los productos con mayores extensiones sembradas, por debajo de los pastos (34.640 ha), el cacao (8.061 ha) y el maíz (6.597 ha) (DGEC, 1963).

En 1973 el banano (20.698 ha) se ubicó como el segundo producto con mayores extensiones ocupadas, por debajo de los pastos (62.205 ha), y por encima del cacao (7.224 ha) y el maíz (5.244 ha) (DGEC, 1973).

Para 1984, el banano si bien incrementó sus áreas sembradas (22.713 ha), siguió como el segundo producto con mayores extensiones, por debajo de los pastos (106.026 ha), pero bastante por encima del arroz (7.243 ha) y los plátanos (4.684 ha) (DGEC, 1984).

Finalmente en el 2014, el banano (41.442 ha) siguió como el segundo producto con mayores extensiones ocupadas, después de los pastos (84.539 ha) pero superando ampliamente a la piña (6.849 ha) y la palma aceitera (5.440 ha) (INEC, 2014).

Lo que se aprecia en estos datos es que el banano ha mantenido una tendencia al crecimiento en sus extensiones de cultivos desde la retirada de la UFco, llegando a incrementarse en 37.180 ha entre 1963 y el 2014; esto le ha permitido consolidarse como el principal producto de exportación en la región Atlántico/Caribe, al superar en extensiones a la piña y la palma africana. El resto de los cultivos mencionados anteriormente, incluyendo a los pastos para el ganado, se dirigen principalmente al mercado interno.

${ }^{4}$ Censos elaborados por la Dirección General de Estadísticas y Censos -DGEC, 1953, 1965, 1974, 1987; y por el Instituto Nacional de Estadísticas y CensosINEC-, 2014. 
La producción bananera de exportación se ha visto favorecida por las políticas económicas de libre comercio instauradas en el país a mediados del decenio de 1980 que impulsaron la internacionalización de la economía y la promoción de las exportaciones, principalmente de aquellos productos capaces de competir en los mercados mundiales y generar divisas, como las frutas, flores y raíces.

A pesar del éxito de la actividad bananera en la región de estudio, reflejado en el crecimiento del área cultivada, se ha producido un significativo daño ambiental porque el monocultivo se caracteriza por apropiarse de extensos terrenos con cobertura vegetal o previamente transformados, por consumir grandes cantidades de agua y aplicar altos volúmenes de agroquímicos, cuyos residuos se filtran al ambiente causando destrucción, alteración y contaminación de los ecosistemas naturales. Esta situación afecta al bienestar de las poblaciones locales, porque se les excluye de la explotación de los recursos que necesitan para asegurar el cumplimiento de sus ciclos productivos y reproductivos.

De acuerdo con Manuel González de Molina (2009), la forma e intensidad en que una unidad productiva se apropia o contamina el medioambiente define el tipo de relación que establece con la naturaleza, la cual es importante en cuanto sobrepase o no la capacidad regenerativa de los ecosistemas y, por tanto, de su sostenibilidad, entendida como la continuidad en el tiempo de los recursos naturales para su explotación por las poblaciones humanas.

Las unidades productivas entablan su relación con la naturaleza a través de un sistema metabólico, al que Víctor Toledo y Manuel González de Molina (2007) llaman metabolismo social. Mediante este sistema formado por cinco procesos bien definidos, las unidades se apropian, circulan, transforman, consumen y excretan materiales y energías provenientes del medio natural. 
Cada uno de los procesos que componen el sistema metabólico se definen seguidamente (recopilados de Toledo y González de Molina, 2007):

1. Apropiación: permite a los grupos humanos obtener las materias, servicios y energías que los individuos y sus artefactos necesitan para mantenerse y reproducirse; la ejecuta la llamada unidad de apropiación, que puede ser un individuo o un artefacto aislado, una familia, una fábrica o un pueblo

2. Transformación: son los cambios realizados a aquello que se extrae de la naturaleza para consumirse en una forma distinta a su original. Se incluyen actividades como el cocimiento de los alimentos, el uso de energías y materiales para realizar artesanías, manufacturas y el funcionamiento de fábricas

3. Distribución: es cuando las unidades de apropiación no consumen todo lo que producen ni producen todo lo que consumen, por lo que los elementos extraídos y transformados inician una circulación entre una o varias sociedades. Participan elementos como los avances en los medios de transporte, los patrones y medios para el intercambio monetario, el desarrollo de los mercados y el avance y desarrollo de la propiedad privada

4. Consumo: participa la sociedad completa con las distintas unidades de apropiación. Está determinado por las necesidades históricas y sociales de los seres humanos junto a los medios para satisfacerlas, los cuales son proporcionados por las unidades de producción y los procesos de Transformación y Distribución

5. Excreción: es cuando las sociedades depositan sus desechos en forma de energías, gases y materiales de vuelta a la naturaleza, participando la sociedad completa junto con las unidades de producción. La principal atención recae sobre la calidad y cantidad de los residuos expulsados, que se definen como amigables o no con la naturaleza, de modo que se sobrepase o no la capacidad de reciclaje y de asimilación de los ecosistemas 
En este contexto, es posible definir a la plantación bananera como una unidad productiva que inicia su ciclo metabólico consumiendo un área natural o previamente transformada, la cual convierte en un campo de cultivo que se apropia de recursos como suelos y agua; culminando el ciclo con la expulsión de las excretas de vuelta al medio natural, que suelen ser residuos de plaguicidas y despojos de las plantas, frutas y del proceso productivo en general.

Para Rafael Cartagena (2008), cuando una unidad productiva establece una relación con la naturaleza sustentada en intensivos procesos de apropiación y excreción, los cuales son los que provocan el mayor daño ambiental al destruir y contaminar los ecosistemas, termina por provocar conflictos socio-ambientales con el resto de sectores sociales presentes en el territorio, porque el daño ambiental excluye a dichos sectores del acceso y explotación de los recursos que aporta la naturaleza y que son indispensables para la subsistencia.

En este contexto, es importante analizar en la región Atlántico/Caribe de Costa Rica la relación entre la producción bananera y el surgimiento de conflictos socio-ambientales a lo largo del tiempo, con el fin de valorar los efectos que esta extensiva e importante actividad agrícola ha tenido sobre el equilibrio de la naturaleza y el bienestar de las poblaciones locales entre 1950 y el 2017, de forma que el análisis abarque desde el resurgimiento del desarrollo bananero durante la segunda mitad del siglo XX hasta la actualidad.

Dicha valoración se ha realizado mediante la revisión y análisis en trayectoria de datos y documentos estadísticos, teóricos y técnicos, correspondientes al período de estudio, donde se evidencia el desarrollo de la producción bananera en la región Atlántico/Caribe, junto a sus características y los principales efectos ambientales y sociales resultantes. 
La región Atlántico/Caribe está compuesta por la totalidad territorial de la provincia de Limón; es la única sobre el litoral Caribe costarricense (ver mapa 1), por lo que permite la comunicación a través del mar Caribe con el Océano Atlántico y las principales metrópolis y mercados mundiales.

\section{Mapa 1. Región Atlántico/Caribe}

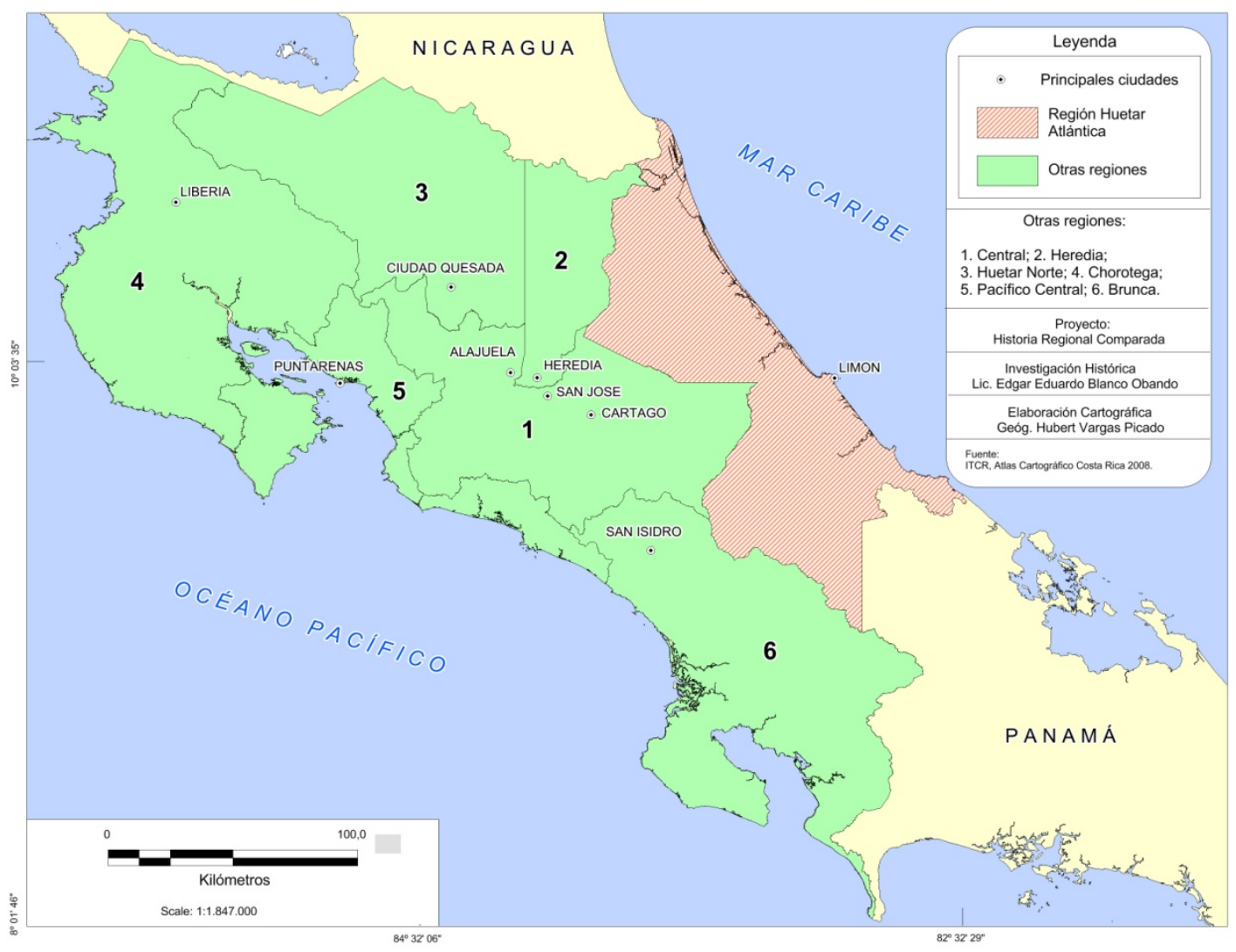

Figura 1: Mapa de la Región Atlántico/Caribe (tomado de: ITCR [2008]; reproducido con permiso) 


\section{Conflictos socio-ambientales}

Los conflictos socio-ambientales son disputas entre actores sociales causadas por una determinada relación establecida con la naturaleza, que alguno de los actores percibe como perjudicial; esta percepción es el catalizador del enfrentamiento.

Para Manuel González de Molina (2009), es el desigual acceso al medio ambiente y sus recursos lo que provoca la competencia y conflictividad entre los actores sociales; por lo tanto, el conflicto ambiental surge dentro del manejo y distribución de los bienes y servicios que brinda la naturaleza, cuando se considera que atentan contra la subsistencia de un grupo social en específico. Por su parte, los conflictos sociales son resultado de una desigual asignación de energías y materiales, y de los residuos generados dentro del metabolismo social, en el contexto de los acuerdos sociales y de los efectos del metabolismo sobre las estructuras de la sociedad.

Lo común es que en los enfrentamientos participe una importante diversidad de actores, con niveles diversos de impacto (local, regional, nacional o incluso global), y que se involucren empresas nacionales, corporaciones transnacionales, sociedades civiles, gobiernos regionales y Estados (Pakkasvirta, 2009).

La conflictividad puede surgir dentro de cada uno de los procesos del metabolismo social, pero se presenta en mayor medida en los procesos de apropiación y excreción, porque son los que producen mayor impacto sobre la estabilidad de los ecosistemas y la disponibilidad sus recursos (Cartagena, 2008).

Para Anthony Goebel (2010), el crecimiento económico basado la explotación de la naturaleza produce daños ambientales no compensados por las políticas económicas ni por el cambio tecnológico; estos daños reducen las posibilidades de determinados grupos de satisfacer sus necesidades materiales de vida, por lo que se ven obligados a luchar para asegurar la subsistencia. 
Por su parte, Martínez Alier (2008) define los conflictos ambientales o ecológico-distributivos como producto de la relación depredadora de la economía humana con el medio ambiente, y se explican desde el metabolismo social. Los actores más poderosos, los que rigen los procesos económicos con una influencia tanto local como regional, nacional y global, realizan una apropiación intensiva de los recursos y un depósito elevado de residuos sobre el medio natural, con lo que terminan limitando para los demás sectores de las sociedades su derecho al acceso a la naturaleza.

$\mathrm{Si}$ bien, es posible sostener que la conflictividad surge en relación con el deseo de conservar la naturaleza o alcanzar una distribución más justa de sus bienes y servicios, los actores inmersos pueden justificar y valorar el conflicto desde diversos discursos o lenguajes formales como el de los economicistas, del comercio internacional, de los ecologistas, o el de justicia social. Pero también pueden recurrir a discursos menos formales que apelan a los derechos territoriales indígenas, la identidad o la religión. En cualquier caso, para los colectivos excluidos del reparto ecológico, la necesidad de sobrevivir es lo que los lleva a luchar para conservar la naturaleza, poseyendo o no una conciencia o lenguaje ambiental que justifique la movilización (Martínez-Alier, 2006).

También es común que entre los actores inmersos en la conflictividad coexistan diversas valoraciones, creencias, perspectivas y percepciones sobre lo que origina la movilización social, aunque no se expresen dentro del discurso oficial (Viales y Marín, 2012). Por lo tanto, en la conflictividad socio-ambiental es usual el encuentro de una amplia heterogeneidad de actores y valores, así como de diversas justificaciones para la acción colectiva. Por tanto, para el análisis del conflicto socio-ambiental lo mejor es partir de una amplia tipología de conflictos y actores, de causas y consecuencias.

\section{Tipología de los conflictos socio-ambientales}


Al originarse la conflictividad dentro de la relación social establecida con el medio ambiente, se supone que el nivel de sustentabilidad ${ }^{5}$ incide en el surgimiento de los conflictos. Pero esta conexión no siempre es percibida o valorada por los actores involucrados, ya que éstos pueden justificar su movilización tanto por la defensa del medioambiente como por cualquier otra razón.

Según Martínez-Alier (2006), en los países pobres la reacción de los grupos más vulnerables en defensa del medioambiente -ante su acaparamiento o destrucción por parte de modernas unidades productivas capitalistas- corresponde a su interés por mantener el acceso a los bienes y servicios de la naturaleza que sustentan sus ciclos reproductivos, y no así por intenciones de preservar la naturaleza para el bien común. Lo usual es que predomine el deseo de las poblaciones por mantener sus formas de vida y la biomasa que las sostiene.

González de Molina, Soto y Garrido (2015) señalan que los conflictos ambientales se dirigen a lograr cambios en el metabolismo social e impulsar su evolución, que no siempre son inmediatos o radicales, sino que tienden a evidenciar los efectos sobre el medioambiente o a señalar el cambio de metabolismo y, por tanto, del nivel de sustentabilidad vigente. Es en este contexto de modificación de la forma de manejo de los recursos y de los niveles de sustentabilidad de los ecosistemas donde se deben tipificar los conflictos ambientales y los motivos de la protesta social.

Para González de Molina (2009), en los conflictos ambientales se pueden diferenciar los conflictos de tipo distributivo, denominados como ambientales; y conflictos de tipo reproductivo, denominados ambientalistas. En los primeros no se pretende la sustentabilidad y pueden emplearse diversos lenguajes dentro de la protesta; mientras que en los segundos sí se pretende la sustentabilidad y también pueden

\footnotetext{
5 Nota del Revisor: Término que es de uso común en Latinoamérica, sinónimo de "sostenible" o "sostenibilidad" que son los términos que se utilizan en España.
} 
presentarse diversos lenguajes de la protesta. Finalmente, están los conflictos denominados como ecologistas, que son de tipo reproductivo, pretenden la sustentabilidad y emplean un discurso ecologista explícito.

También es usual el surgimiento de conflictos entre grupos con tipos distintos de metabolismo, que luchan por imponer o defender su sistema de relación con la naturaleza; estos conflictos son definidos por González de Molina, Soto y Garrido (2015) como intermetabólicos, y corresponden al tipo de luchas como las de campesinos, con un metabolismo orgánico implícito, contra la imposición del metabolismo industrial por parte de sectores capitalistas con principios económicos, sociales y ecológicos muy distintos. A su vez están los conflictos intra-metabólicos, que corresponden a grupos sociales enfrentados por la atribución de los bienes y servicios ambientales, pero que interactúan dentro de una misma organización metabólica ya consolidada.

\section{Cuadro No. 1}

\section{Tipología de la conflictividad ambiental}

\begin{tabular}{|c|c|c|l|}
\hline Denominación & \multicolumn{1}{|c|}{$\begin{array}{c}\text { Tipo de } \\
\text { conflicto }\end{array}$} & $\begin{array}{c}\text { Metabolismo } \\
\text { social }\end{array}$ & \multicolumn{1}{|c|}{ Lógica/discurso } \\
\hline Ambientales & Distributivos & Intra-metabólicos & $\begin{array}{l}\text { Sin pretensión de } \\
\text { sustentabilidad/con } \\
\text { lenguajes diversos de } \\
\text { la protesta }\end{array}$ \\
\hline Ambientalistas & Reproductivos & Inter-metabólicos & $\begin{array}{l}\text { Con pretensión de } \\
\text { sustentabilidad/con } \\
\text { lenguajes diversos de } \\
\text { la protesta }\end{array}$ \\
\hline Ecologistas & Reproductivos & Inter-metabólicos & $\begin{array}{l}\text { Con pretensión de } \\
\text { sustentabilidad/con } \\
\text { discurso ecologista } \\
\text { explícito }\end{array}$ \\
\hline
\end{tabular}

Fuente: González de Molina, 2009: 242. 
En general, los conflictos entre actores sociales por el ambiente involucran una amplia gama de sectores que se enfrentan bajo distintas justificaciones, valoraciones de su existencia y concepciones de la naturaleza; por lo tanto, para el adecuado análisis de este tipo de conflictos, lo adecuado es emplear etapas metódicas que permitan abarcar y comprender el dinamismo de la conflictividad, su estructura, origen, diversidad de los actores y la complejidad de los discursos y propuestas.

\section{Propuesta analítica}

Con base en el estudio de Viales Hurtado y Marín Hernández (2012), se propone abordar el conflicto socio-ambiental mediante el empleo de las siguientes etapas metódicas, que dirigen el proceso analítico desde la comprensión plena del origen y desarrollo del conflicto, la identificación y caracterización de los actores junto con su rol y relación, la determinación de los lenguajes que se emplean, y finalmente una valoración del conflicto y de los resultados finales.

Etapas metódicas a seguir:

- Se entiende el conflicto como producto del metabolismo social, con consecuencias sobre la salud y el ambiente. La controversia y la conflictividad están presentes en cada fase del metabolismo social

- Se analizan las diferentes interpretaciones del conflicto en el tiempo, que son elaboradas por los actores dentro del conflicto sobre las consecuencias de este: opiniones de expertos, empresarios, académicos, gobiernos, partidos políticos, sindicatos, población afectada, etc. 
- Se clasifican los actores sociales involucrados en el conflicto, con respecto al espacio desde el cual participan, junto a sus intereses: ambientalistas, campesinos, indígenas, pobladores, empresarios, Estado, partidos políticos, sociedad civil, etc.

- Se construye una cronología de los conflictos con una valoración de multi-criterio, de modo que se aprecie la evolución de las posiciones de los actores, así como los cambios en los diferentes lenguajes empleados para valorar o referirse al conflicto

- Se estudian las decisiones finales, las que llevaron al acuerdo resolutivo del conflicto: la forma en que se tomaron, la metodología utilizada, los lenguajes de valoración que fueron excluidos, la forma en que se ejerció el poder tanto legal como ilegal, el proceder y valoración de los actores, etc.

Esta propuesta analítica abarca las diferentes dimensiones que inciden en el origen y desarrollo de un conflicto socio-ambiental, y su empleo facilita los elementos metodológicos necesarios para identificar a los sectores involucrados junto a sus valores, al igual que su discurso y comportamiento a lo largo del conflicto.

En países como los latinoamericanos, cuyos ecosistemas sustentan el desarrollo de las sociedades locales y el crecimiento de poblaciones industrializadas del primer mundo, se considera que la conflictividad socio-ambiental ha alcanzado una mayor importancia y una mayor valoración de su impacto social, debido a su relación con la globalización de la economía de mercado, que ha facilitado la expansión de las grandes unidades capitalistas que ejercen poder e influencia sobre poblaciones enteras y sobre los mismos Estados. 


\section{La actividad bananera y sus impactos ambientales}

En la región Atlántico/Caribe el banano se produce principalmente para la exportación, por lo que su cultivo abarca grandes extensiones de terrenos y es sometido a estrictos estándares internacionales de calidad, que se mantienen mediante la aplicación de elevados volúmenes de plaguicidas durante todo el ciclo productivo.

El banano suele ser atacado por nematodos como el Radophulus Similis; enfermedades como la Sigatoka negra que es causada por el hongo Mycosphaerella Fijiensis; así como por numerosos insectos y malezas. Para el combarte de las plagas, los productores aplican enormes cantidades de plaguicidas, entre 30 y 49 $\mathrm{kg}$ de ingredientes activos por hectárea al año. Esta situación convierte al banano en uno de los cultivos que utiliza mayores cantidades de agroquímicos en Costa Rica (Ministerio de Salud, 2003).

La aplicación intensiva de plaguicidas lleva al monocultivo a establecer un metabolismo insustentable, debido a que por el proceso de excreción se depositan enormes cantidades de residuos de los plaguicidas sobre los ecosistemas, sobrepasando sus capacidades regenerativas y dañando incluso la salud de las personas. Estos daños sobre la naturaleza y las personas se han mantenido a lo largo del tiempo, sin embargo, es a partir de la década de 1990 que reciben mayor atención y se incrementa el número de denuncias, debido al crecimiento del interés público por los temas ambientales y los impactos de las actividades productivas sobre el medio natural.

Así, a finales del decenio de 1970 se denunció la esterilización de cerca de 1.500 obreros bananeros a causa de la exposición a los nematicidas fumazone y nemagón, compuestos por la nociva sustancia activa dibromocloropano, aplicados intensivamente en las bananeras caribeñas entre 1967 y 1979 (Ministerio de Salud, 2003).

A inicios del decenio de 1990 ocurrió una muerte masiva de peces en ríos de Matina, a causa de su contaminación por el nematicida 
phorate, de uso común en las fincas bananeras (Fernández-González, Boyce, Fürst y Segura, 1994).

En 1996 se reportó en la provincia de Limón la intoxicación de 375 personas a causa de la filtración de plaguicidas al ambiente; esta cantidad de afectados significó el 47,3\% del total de intoxicados por contacto con plaguicidas en el país para dicho año (Programa Estado de la Nación, 1997).

Para finales de la década de 1990 se estimó, entre los trabajadores de las bananeras, una presencia importante de problemas de melanoma, cáncer de pene, cáncer de cérvix, leucemia y altos riesgos de engendrar hijos con malformaciones congénitas y riesgos de padecer cáncer (Ramírez y Cuenca, 2002).

A su vez, entre 1999 y el 2002 la tasa de incidencia de intoxicaciones promedio en Costa Rica fue del 17,6\%; mientras que en la provincia de Limón fue del 31,6\%, la segunda más elevada del país, por debajo solo de Puntarenas (41,6\%) (Ministerio de Salud, 2003).

En el 2002 se determinó que muchas de las fuentes hídricas superficiales dentro de zonas de cultivo bananero en Limón, presentaron elevadas concentraciones de plaguicidas, incluso superiores a los niveles ambientalmente tolerados (Programa Estado de la Nación, 2003).

Posteriormente, en el 2009 se diagnosticaron en el cantón de Talamanca grupos de niños con altas concentraciones de Clorpirifós, insecticida diseñado para causar la muerte por colapso del sistema nervioso, que en los humanos suele producir daños neurológicos y déficit en la función cognitiva (Programa Estado de la Nación, 2010).

Para el 2010 se comprobó que, en las zonas de influencia de las plantaciones bananeras, la diversidad de bosques e insectos se reduce severamente, y que las fuentes hídricas presentan altas concentraciones de insecticidas, funguicidas y plaguicidas (Programa Estado de la Nación, 2011). 
En el 2017, en Laguna Madre de Dios en Batán, se dio una muerte masiva de peces, crustáceos y reptiles, en el río Pacuare, uno de los más importantes del país, atribuida a su contaminación por los funguicidas azoxistrobina epoxiconazol, difeconazol, tiabendazol, los herbicidas ametrina, hexazinona, diuron, y el insecticida diazon; provenientes según empresarios turísticos y vecinos, de las plantaciones cercanas de banano, piña y arroz (Quirós, 2017).

Ante esta situación de persistentes daños por las excretas de las bananeras, reflejados en la contaminación de ecosistemas y la resultante exclusión de las poblaciones locales sobre su explotación, junto con la afectación de la salud de las personas, los sectores sociales se movilizaron para exigir la regulación del impacto ambiental del monocultivo, al considerar que su producción atenta contra sus condiciones de subsistencia.

\section{Principales conflictos surgidos}

La excreción masiva de residuos de los plaguicidas por parte de las plantaciones bananeras ha provocado una contaminación importante del medio ambiente y ha afectado a la salud de las personas de una manera constante en el tiempo; esta situación ha provocado la movilización de diferentes sectores de la sociedad civil ante el Estado y las empresas agroproductoras, al sentirse excluidos del acceso al medio natural y ver dañadas sensiblemente sus condiciones de subsistencia.

La forma de lucha presentada con mayor frecuencia por las poblaciones caribeñas ha sido la organización y movilización multitudinaria en espacios públicos, junto a la interposición de demandas en las instancias judiciales en contra de empresas e instituciones públicas, para que se les obligue a actuar de acuerdo con el cuidado del ambiente y la protección de la salud de los habitantes.

\section{Acciones emprendidas}


Para el final de la década de 1970, la Iglesia Católica limonense - a través de los organismos parroquiales y los grupos eclesiásticos de base, con el apoyo del Vicario Apostólico de Limón- se movilizó y denunció ante la opinión pública la destrucción de la naturaleza y el daño al bienestar de las personas a causa del cultivo descontrolado del banano. Las denuncias incorporaron la necesidad de expandir la conciencia ambiental entre la sociedad como forma de regular los efectos nocivos del monocultivo, y fomentar el debate entre las asociaciones de productores bananeros sobre la necesidad de reformular las condiciones productivas, de manera que se redujera la destrucción del medio ambiente (Fernández-González et al, 1994).

Entre finales del decenio de 1980 e inicios del de 1990, bajo el liderazgo de las agrupaciones religiosas limonenses, se formó el Foro Emaús, que unió a grupos comunales, laborares, estudiantiles, gremiales y ecologistas, con jurisdicción tanto regional como nacional, bajo el objetivo de defender la naturaleza y la salud pública ante el expansionismo descontrolado de las plantaciones bananeras. Desde el Foro Emaús se denunció la contaminación de las fuentes hídricas con químicos y desechos inorgánicos y orgánicos (3.500 toneladas de plásticos para proteger los racimos de bananos y gran cantidad de fruta de rechazo y pinzotes), la tala de bosques (entre 4 y 6 mil ha), desvío y destrucción de cauces fluviales para drenajes, el uso en fumigaciones aéreas con agroquímicos reconocidamente tóxicos como el Paracuat, y daños severos a la salud de las personas: alergias y esterilidad. (Fernández-González et al, 1994)

Para el año 2001, el Foro Emaús exigió prohibir el registro, venta y uso del herbicida Paraquat, debido a su alto nivel de toxicidad, y lo señaló como responsable de la muerte de 15 personas entre 1980 y 1991 (Guerén 2001). 
En el 2004, la Asociación de Desarrollo para la Ecología de Limón interpuso una denuncia ante el Tribunal Centroamericano del Agua, en contra de la Standard Fruit Company, el Ministerio de Obras Públicas y Transportes, la Dirección General de Aviación Civil y el Ministerio de Agricultura y Ganadería. Con la denuncia estas instituciones fueron acusadas de practicar y permitir la fumigación aérea de bananales al margen de las reglas mínimas de precaución y prevención, al realizarla de forma cercana a viviendas, centros educativos y fuentes hídricas (Tribunal Centroamericano del Agua, 2004).

En el 2017, grupos de pescadores de las localidades de Laguna Madre de Dios y de Barra Pacuare realizaron una manifestación en San José denunciando la contaminación con agroquímicos de los lugares de pesca y hábitat. Los pescadores denunciaron que numerosas agroempresas desechan estas sustancias sobre las fuentes hídricas, por lo que exigieron al Estado un mayor control sobre el uso de agroquímicos en la zona, de modo que se preserve la flora y la fauna de cuya explotación dependen para subsistir (Matarrita, 2017).

\section{Actores involucrados}

En los conflictos socio-ambientales analizados, se mantuvo la participación constante de actores muy diversos, pertenecientes a diferentes sectores sociales, ámbitos geográficos de acción y con intereses distintos.

\section{Entidades locales}

En el ámbito propiamente local y civil, mantuvieron una participación constante las organizaciones de comunidades, grupos de campesinos, la Iglesia Católica, sindicatos y gremios agrícolas, y asociaciones de estudiantes. 


\section{Entidades gubernamentales}

A nivel gubernamental, los principales entes involucrados fueron el Ministerio de Obras Públicas y Transportes, la Dirección General de Aviación Civil, el Ministerio de Agricultura y Ganadería, la Presidencia de la República, el Ministerio de Salud y el Ministerio del Ambiente; todos pertenecientes al gobierno central.

\section{Entidades judiciales}

Las entidades judiciales involucradas en los conflictos, fueron a nivel nacional la Corte de Justicia y el Tribunal Ambiental Administrativo, y a nivel internacional el Tribunal Centroamericano del Agua.

\section{Entidades académicas}

Las entidades académicas que se involucraron en los conflictos fueron la Universidad de Costa Rica, de carácter público, y la entidad privada Escuela de Agricultura de la Región del Trópico Húmedo.

\section{Entidades ecologistas y defensoras de la justicia social}

En los conflictos participaron entidades ecologistas y defensoras de la justicia social con operación regional, nacional e internacional, como fueron la Asociación de Desarrollo para la Ecología de Limón, el Foro Emaús, la Federación Conservacionista de Costa Rica y el Comité de Miembros de la Unión Internacional de Conservación de la Naturaleza.

\section{Entidades empresariales}

Las empresas involucradas fueron las bananeras, agrupadas en entidades con rango de acción nacional, como la Comisión Ambiental Bananera, la Cámara Nacional de Bananeros y la Corporación Bananera Nacional; junto con la transnacional Standard Fruit Company. 


\section{Valoraciones de los conflictos}

Los diferentes actores involucrados presentaron diferentes valoraciones de los conflictos, de acuerdo a sus intereses y márgenes de acción. Para los sectores opuestos al actuar de las bananeras, como las poblaciones locales, asociaciones ecológicas y por la justicia social, los conflictos fueron resultado de la falta de controles estatales sobre el funcionamiento de las plantaciones, que permiten a los empresarios aplicar plaguicidas desde objetivos meramente mercantilistas, contemplando solo el incremento de la producción y las ganancias, sin considerar el daño al ambiente y a la salud de las personas que de sus acciones se derivan.

La continua presencia de la conflictividad ambiental, evidencia o un desinterés o una incapacidad estatal para solucionar sus causas, a pesar de las consecuencias mostradas sobre la naturaleza y la población; el desinterés se evidencia en la persistente evasión de sus responsabilidades por parte de las instituciones públicas encargadas de la conservación del medio ambiente y proteger la salud de las personas (Roldán, 2008).

En el 2011 la delegación del Ministerio de Salud de la región Caribe, apenas cumplía con registrar los casos de intoxicación que reportaban los hospitales de la región, sin emprender acciones para controlar el uso de los agroquímicos y sus consecuencias (Semanario Universidad, 2011).

En el 2012 se evidenció que el uso del insecticida endosulfán, prohibido en muchos países por su resistencia y permanencia prolongada en el medio ambiente, al igual que por estar relacionado con la epilepsia y parálisis celebrar, se continuaba en muchas de las plantaciones nacionales, a pesar de que el Estado aseguraba tener bajo control su importación y aplicación (Semanario Universidad, 2012). 
Esta inacción de las entidades públicas, permitió a los vecinos y sus aliados señalar al Estado como el principal responsable de permitir a los empresarios el uso intensivo y descontrolado de los plaguicidas.

Desde el Ministerio de Agricultura y Ganadería se consideró que los conflictos son resultado de la poca modernización del registro nacional de los agroquímicos, cosa que permite su uso bajo normativas antiguas e impide la importación de agroquímicos de última generación, que son los que tienen mayor efectividad en menores cantidades y un mejor perfil ambiental y toxicológico (Chacón, 2017).

Sin embargo, para la organización internacional ecologista Comité de Miembros de la Unión Internacional de Conservación de la Naturaleza (UICN), el desarrollo en el país de monocultivos como el banano, ha carecido de una regulación seria y responsable por parte del Estado, a pesar de los problemas sociales y ambientales que generan (Semanario Universidad, 2012).

Para la Federación Conservacionista de Costa Rica, el Estado suele actuar de acuerdo a las necesidades de las empresas y las cámaras de productores (Chacón, 2017).

De acuerdo con Roldán (2008), el uso intensivo de plaguicidas bajo escaso control público, tiene mucho que ver con el interés del Estado por generar crecimiento económico e incremento de las exportaciones, y con el interés de las empresas por crear ganancias en el corto plazo, por lo que tienden a bajar costos en el uso de tecnología moderna y de bajo impacto ambiental.

De igual forma se señala que existe presión de mercados y fabricantes para el uso de agroquímicos, que estarían obligando al Estado a exonerar de impuestos a muchos de estos productos, permitiendo que en la propaganda se les llame "agentes para la protección de cultivos" y que los registros se realicen en el Ministerio de Agricultura y no en el de Salud (Wessling, Catharina. Aragón, Aurora. Castillo, Luisa. Corriols, Marianela. Chaverri, Fabio. de la 
Cruz, Elba. Keifer, Matthew. Monge, Patricia. Partenen, Timo. Reupert, Clemens. van Wendel de Joode, Berta, 2003).

\section{Lenguajes utilizados}

Los sectores defensores del ambiente emplearon durante los conflictos un discurso ecologista como sustento a su lucha, al percibir que las excretas de las bananeras contaminan la naturaleza y los excluye del acceso a sus recursos, al igual que daña sus condiciones de salud.

Por su parte, los bananeros presentaron un lenguaje economicista, sosteniendo que su actividad tal como la ejecutan, es esencial para generar empleos y desarrollar la región. También presentaron un lenguaje sustentable y de compromiso con la conservación del medio ambiente, cuando percibieron que las movilizaciones atentaban contra sus intereses, como forma de reducir los niveles de conflicto y hacer ver que incorporaban medidas ambientales para reducir el impacto del monocultivo sobre la naturaleza.

En este contexto, al inicio del decenio de 1990, los bananeros crearon la Comisión Ambiental Bananera -integrada por empresas independientes, la Cámara Nacional de Bananeros, la Escuela de Agricultura de la Región del Trópico Húmedo y la Corporación Bananera Nacional- para mejorar sus prácticas productivas y reducir el impacto ambiental mediante un mejor manejo de los desechos, la reducción de la contaminación de las aguas, un mayor control del uso de los agroquímicos y reforestación de riberas y zonas limitantes con áreas protegidas; a estas acciones los empresarios le llamaron la reconversión ecológica (Fernández-González et al, 1994).

Por su parte, algunas instituciones públicas presentaron un discurso a favor del crecimiento económico generado por el monocultivo y de sus aportes para las economías regional y nacional, legitimando su actuar y restando importancia a los conflictos.

B

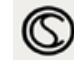

DOI. 10.1344/ACS2018.7.8 
Desde el Ministerio de Salud se resaltó la importancia de los agroquímicos en el desarrollo de la agricultura, por lo que imponer mayores medidas regulatorias es atentar contra la estabilidad de las unidades productivas. Por su parte, desde el Ministerio de Agricultura se definió que las muertes relacionadas con los plaguicidas fueron causadas por su ingestión con fines de suicidio, y que las movilizaciones en contra de los agroquímicos se deben a intereses de las asociaciones ecologistas, que reciben dinero de organizaciones europeas por realizar estas protestas (Guerén, 2001).

En el 2017 desde el Ministerio de Agricultura y Gandería, se presentó la propuesta de modernizar la legislación del uso de agroquímicos, de manera que se puedan importar los de nueva generación, que requieren menores dosis y número de aplicaciones (Chacón, 2017); sin embargo, esta propuesta sigue sin materializarse.

Se aprecia, así, que el discurso gubernamental ha sido similar al de los empresarios, basado en mantener el uso intensivo de plaguicidas para no afectar el crecimiento económico, pero incorporando algunas medidas que puedan reducir el impacto ambiental del monocultivo; manteniendo el predominio del interés comercial sobre el social y el ambiental.

\section{Solución de los conflictos}

La inacción por parte de las instituciones públicas ha permitido la permanencia de la conflictividad ambiental, asegurando las condiciones para que las plantaciones bananeras continúen excretando sus residuos bajo muy pocos controles, a pesar del daño causado sobre el equilibrio de los ecosistemas y la salud pública. Por lo tanto, los conflictos ambientales en la región Atlántico/Caribe no han alcanzado solución alguna, a pesar de la movilización social y las denuncias judiciales interpuestas. Sin embargo, las presiones ejercidas han logrado que ciertas empresas incorporen mayores controles 
ambientales, y adquieran un mayor compromiso por el bienestar de la naturaleza y la población local, esto parece ser resultado del interés de las empresas por mantener su posicionamiento en los mercados, y no así por las presiones públicas o por una mayor conciencia ambiental adquirida.

A pesar de la interposición de denuncias ante los tribunales de justicia, esto tampoco ha logrado la solución de los conflictos, debido a que en el país los procesos judiciales son largos; por ejemplo, en el Tribunal Ambiental Administrativo la cantidad de demandas que ingresan sobrepasa la capacidad de los funcionarios para atenderlas, por lo que una buena parte de las denuncias presentan la particularidad de llevar hasta décadas esperando su solución (Arguedas, 2016). Unido a esta situación, las resoluciones emitidas no siempre son acatadas por los aludidos.

\section{Balance del conflicto socio-ambiental por el cultivo del banano}

Durante el período de estudio, la plantación bananera estableció un metabolismo insustentable con la naturaleza en la región Atlántico/Caribe, el cual la ha transformado y contaminado de manera significativa, principalmente mediante el proceso de excreción, al depositar en el medio ambiente altas cantidades de residuos de plaguicidas, que además de alterar los ecosistemas, daña sensiblemente la salud de los habitantes.

La principal causa de la instauración de este metabolismo por parte de la unidad bananera, ha sido el establecimiento de un sistema productivo basado en el consumo intensivo de plaguicidas para alcanzar estándares internacionales de calidad y un nivel productivo altamente competitivo; esto unido a un actuar gubernamental complaciente, que ha privilegiado el crecimiento económico sobre el bienestar ambiental y social. 
La conflictividad socio-ambiental es resultado de esta relación insustentable establecida por las bananeras con la naturaleza, y la acción colectiva aparece cuando a los pobladores locales se les hace patente de que el funcionamiento de las bananeras atentaba contra la continuidad de la biomasa y demás condiciones ecológicas que necesitan para subsistir.

Aunque la movilización colectiva se dirigió al reparto equitativo del medio natural, los actores inmersos, tanto empresas como vecinos y sus aliados, emplearon un discurso ecologista para justificar sus acciones; esto parece deberse al peso que tiene en Costa Rica la defensa de la naturaleza para atraer apoyo y justificar cualquier acción, por lo que los diferentes actores lo explotaron para obtener mayores dividendos.

A pesar de la justificación ecologista, el principal interés de los sectores enfrentados fue la subsistencia y permanencia de sus metabolismos y estilos de vida, por lo que los conflictos se catalogan más que reproductivos, de tipo distributivo e intra-metabólico.

A su vez, la participación de empresas transnacionales y entidades judiciales internacionales, dieron a los conflictos un ámbito de influencia global, trascendiendo así el nivel de acción regional como nacional.

La permanencia en el tiempo de este tipo de conflicto se achaca a la inacción estatal y al poco interés de las bananeras por modificar sus procesos de excreción y, aunque esta situación llevó a la judicialización de los conflictos, las Cortes tampoco aseguraron su finalización, debido a que no contaron con los recursos y ni el tiempo suficiente para dar los veredictos correspondientes.

Lo más probable es que la conflictividad socio-ambiental en la región Atlántico/Caribe continúe hasta que se regule el actuar de las bananeras y se modifique su relación con la naturaleza, de modo que no atente contra la continuidad de los ecosistemas ni contra la salud pública; sin embargo, se cree que la principal vía para lograr esta 
situación es que el Estado ejerza con fuerza la regulación ambiental del monocultivo, o que los empresarios decidan producir sustentablemente por su propia cuenta; ambas posibilidades no parecen poder concretarse ni en el corto ni en el mediano plazo.

\section{Bibliografía}

Arguedas, Diego. (2016). Casos contra Piñeras se añejan atorados en Tribunal Ambiental. Semanario Universidad, País, 17 de febrero, p4 Cartagena, R. (2008). Apuntes sobre el metabolismo socio-ambiental y los conflictos ambientales. Revista Centroamericana de Ciencias Sociales, 5(2).

Chacón, Vinicio. (2017). Gobierno diseñó sistema de registro de agroquímicos. Semanario Universidad, País, p10, 8 de febrero.

Dirección General de Estadísticas y Censos-DGEC-. (1953). "Censo Agropecuario 1950”. Ministerio de Economía y Hacienda. San José, Costa Rica.

Dirección General de Estadísticas y Censos-DGEC-. (1965). "Censo

Agropecuario 1963”. Ministerio de Economía y Hacienda. San José, Costa Rica.

Dirección General de Estadísticas y Censos-DGEC-. (1974). "Censo

Agrícola 1973”. Ministerio de Economía, Industria y Comercio. San José, Costa Rica.

Dirección General de Estadísticas y Censos-DGEC-. (1987). “Censo

Agrícola 1984." Ministerio de Economía, Industria y Comercio. San José, Costa Rica.

Fernández-González, Álvaro. Boyce, James. Fürst, Edgar. Segura, Olman. (1994). "Café y desarrollo sostenible: del cultivo agroquímico a la producción orgánica en Costa Rica." Funda UNA, Heredia, Costa Rica.

Goebel, A. (2010). Ecologismo de los pobres y marginalidad social: Vehículos de complementariedad y puentes dialógicos. Reflexiones, 89(1), 127-142.

González de Molina, M. (2009). "Sociedad, naturaleza, metabolismo social. Sobre el estatus teórico de la historia ambiental". En: R. (Loreto 
López, Agua, poder urbano y metabolismo social (pág. 217-243).

México: Instituto Ciencias Sociales y Humanidades.

González de Molina, M. Soto, D. Garrido, F. (2015). Los conflictos ambientales como conflictos sociales. Una mirada desde la ecología política y la historia. Ecología Politica, (50), 31-38.

Guerán, Pablo. (2001). Exigen prohibir uso de herbicida. Nación, Nacionales, pág 5, 24 de febrero, San José, Costa Rica. Instituto de Estadísticas y Censos -INEC- (2014). "VI Censo Nacional Agropecuario.” INEC, San José, Costa Rica.

León, Jorge. (2012). "Económica de Costa Rica en el siglo XX. Tomo II: La economía rural." Instituto de Investigaciones en Ciencias Económicas y Centro de Investigaciones Históricas de América Central, Universidad de Costa Rica. San José, Costa Rica.

Martínez-Alier, J. (2006). El ecologismo de los pobres. En Archivo Chile. Chile: Centro de Estudios Miguel Enríquez, CEME.

Martínez-Alier, J. (2008). Conflictos ecológicos y justicia ambiental. Papeles, (103), 11-27.

Matarrita, Mónica. (2017). Pescadores limonenses anuncian marcha. Diario Extra, nacionales, p12, 28 de agosto Ministerio de Salud. Organización Panamericana de la Salud. Oficina Regional de la Organización Mundial de la Salud. (2003). Efectos de los plaguicidas en la salud y el ambiente en Costa Rica. Ministerio de Salud, San José, Costa Rica.

Montero, Andrea. Viales, Ronny. (2010). "La construcción sociohistórica de la calidad del café y del banano de Costa Rica. Un análisis comparado 1890-1950”. Librería Alma Mater, San José, Costa Rica.

Pakkasvirta, J. (2009). Conflictos medioambientales y estudios latinoamericanos. El caso de la pastera de Fray Bentos en Uruguay. En H. Cairo y J. Pakkasvirta (Comps.), Estudiar América Latina: Retos y perspectivas. Costa Rica: Editorial Librería Alma Mater.

Programa Estado de la Nación. (1997). "III Informe Estado de la Nación en

Desarrollo Humano Sostenible. Capítulo 4: Armonía con la Naturaleza." Programa Estado de la Nación. San José, Costa Rica.

Programa Estado de la Nación. (2003). "IX Informe Estado de la Nación en Desarrollo Humano Sostenible. Capítulo 4: Armonía con la Naturaleza.” Programa Estado de la Nación. San José, Costa Rica. 
Programa Estado de la Nación. (2010). "XVI Informe Estado de la Nación en Desarrollo Humano Sostenible. Capítulo 4: Armonía con la Naturaleza”. Programa Estado de la Nación. San José, Costa Rica.

Programa Estado de la Nación. (2011). "XVII Informe Estado de la Nación en Desarrollo Humano Sostenible. Capítulo 4: Armonía con la Naturaleza.” Programa Estado de la Nación. San José, Costa Rica.

Quirós, Bharley. (2017). Agroquímicos provocan matanza de peces en río Pacuare. Diario Extra, Nacionales, p6, 20 de agosto

Ramírez, Vanessa. Cuenca, Patricia. (2002). Daño del ADN en trabajadoras bananeras expuestas a plaguicidas en Limón, Costa Rica. Revista de Biología Tropical, 50 (2), pp 507-518

Roldán, Carmen. (2008). Agricultura: tendencias recientes e implicaciones ambientales. Un año de crisis climática y alimentaria. XIV Informe Estado de la Nación en Desarrollo Humano Sostenible. Programa Estado de la Nación, Costa Rica.

Rosario, Reina. (2015). Identidades de la población de origen jamaiquino en el Caribe Costarricense (segunda mitad del siglo XX). 1er edi, Cocolo Editorial

Semanario Universidad. (2011). Costa Rica alcanza récord mundial en consumo de Veneno. País, 21-11-2011, Universidad de Costa Rica. San José, Costa Rica.

Semanario Universidad. (2012). Peligroso insecticida es utilizado en 41 cultivos. País, 25-01-2012, Universidad de Costa Rica. San José, Costa

Toledo, V. y González de Molina, M. (2007). El metabolismo social: Las relaciones entre la sociedad y la naturaleza. En F. Garrido, M. González, J. Serrano y

J. Solana (eds), El paradigma ecológico en las Ciencias Sociales, pp 150-220. Barcelona: Edit Icaria.

Tribunal Centroamericano del Agua. (2004). Resumen Ejecutivo de Casos, Segunda Audiencia de Juzgamiento 15-19 marzo, 2004, COSTA RICA -

Fumigación aérea en finca bananera Carrandí en la comunidad de Larga distancia, Matina, Limón. Tribunal Centroamericano del Agua, San José, Urkidi, L. (2010). A glocal environment movement against gold minning: Pascua-Lama in Chile. Ecological Economics, (70), 219-227.

Viales-Hurtado, R. y Marín-Hernández, J. J. (2012). Los conflictos ecológico-distributivos en Puntarenas: El caso de la mina Bellavista 
de Miramar. Una aproximación inicial. Diálogos, volumen especial en homenaje a Bernard Vincent, 243-286.

Wessling, Catharina. Aragón, Aurora. Castillo, Luisa. Corriols, Marianela. Chaverri,

Fabio. de la Cruz, Elba. Keifer, Matthew. Monge, Patricia. Partenen, Timo. Reupert, Clemens. van Wendel de Joode, Berta. (2003). Manejo Integrado de Plagas y Agroecología, N·68, pág. 7-18. 